\title{
A PRÁTICA DE ENFERMAGEM EM UMA UNIDADE DE QUEIMADOS: ANÁLISE DOS DISCURSOS DOS ENFERMEIROS*
}

\author{
Lídia Aparecida Rossi**
}

\begin{abstract}
RESUMO: Este estudo teve como objetivo analisar a prática de enfermagem em uma Unidade de Queimados. Essa análise foi realizada a partir dos depoimentos de enfermeiros dessa Unidade, obtidos em um estudo anterior através de técnica de observação participante e de registro cursivo(19). Concluímos que os enfermeiros estão insatisfeitos com os salários, com a jomada de trabalho, com o relacionamento médico-enfermeiro e com as situações que envolvem o sofrimento e a agressividade dos pacientes. O cuidado direto parece consistir em uma fonte de satisfação, mas o enfermeiro está dividido entre a realizaçåo desse cuidado e os problemas que têm que resolver. O planejamento da assistência foi ajustado às rotinas do serviço e não às necessidades dos pacientes.
\end{abstract}

ABSTRACT: The objective of the present study was to analyze nursing practice in an Unit of Bumt Patients through declarations of nurses which were obtained in a prior study that utilized the technique of participating observation and cursive register. Authors concluded are not satisfied with their wages, period of work, the relationship between doctors and nurses and situations involving sufferance and agressive patients. However, the direct care appears to be a source of satisfaction, but nurses are divided between this kind of care and the problems they have to solve. The assistance planning was not adjusted to patients' needs, but to work routine.

UNITERMOS: Assistência de Enfermagem - Processo de Enfermagem - Prática de Enfermagem.

\section{INTRODUÇÃO}

A enfermagem é considerada uma profissão bastante jovem, principalmente quando se leva em conta que a sua caracterização como ciência depende de um corpo de conhecimentos específicos que the permita desempenhar suas atribuições com independência, competência e responsabilidade(1).

A profissionalização da enfermagem iniciouse com Florence Nightingale que diferenciou 0 campo de ação da enfermeira e o do médico, explicitou as tarefas que caracterizavam a enfermagem e separou as enfermeiras que adminis- travam das que executavam.

Na visão de LEOPARDI(13), o princípio do controle sobre a execução das tarefas conduziu, na organização do trabalho, à necessidade de hierarquização, o que já se dava de fato no social, pela diferença entre as ladies e as nurses.

Desse modo, surgiu a organização do trabaIho na enfermagem, de forma hierarquizada e fragmentada, cabendo ao enfermeiro o controle, o ensino e a organização dessa prática.

As enfermeiras formadas pelo sistema Nightingale difundiram suas ideias em outros países. No Brasil, a primeira escola de enfermagem foi criada em 1923, fundamentada nesse sistema,

\footnotetext{
- Trabalho elaborado na disciplina: Análise Crítica da Evoluçăo da Assisténcia de Enfermagem do Programa de Pós-Graduaçăo em Enfermagem Interunidades. Escola de Enfermagem de Ribeiráo Preto - Universidade de Sáo Paulo (EERP-USP).

** Enfermeira. Professora Assistente do Departamento de Enfermagem Geral e Especializada da EERP-USP.
} 
para ajudar a controlar as endemias e epidemias que dificultavam o comércio com o exterion(10).

O ensino de enfermagem era dirigido à prática hospitalar, enquanto os enfermeiros deveriam atuar na área de saúde pública, que absorvia grande parte dos enferrneiros formados nessa época(10).

$\mathrm{Na}$ década de quarenta esta situação foi modificada. Houve uma grande expansão da assistência hospitalar, que passou a constituir maior mercado de trabalho para os enfermeiros. Diante da deficiência numérica de enfermeiros frente à expansão dos serviços de saúde, ocorreu um grande aumento no número de escolas de enfermagem, muitas vezes sem recursos financeiros adequados e sem corpo docente eficiente, tanto em número como em qualidade(10).

Assim, o desenvolvimento da enfermagem brasileira ocorreu em ritmo mais acelerado nesse período, quando a industrialização começou a exercer influências marcantes sobre a economia nacional, propiciando mudanças sociais que implicaram em alterações no sistema de saúde.

O hospital privado passou a ser o lugar de maior expressão das políticas de saúde, tanto na quantidade de recursos quanto no grau de cobertura que poderia oferecer. A partir da criação do INPS em 1966, o setor privado tomou-se o eixo principal da organização dos serviços de saúde e foi acompanhado por um complexo desenvolvimento industrial, centrado nas indústrias famacêuticas e de equipamentos médico-hospitalares(4).

O prestígio da tecnologia e da especialização da medicina favoreceu as ações curativas em prejuizo da atenção preventiva.

Com o dimensionamento do hospital como espaço de assistência à saúde, este passou a absorver um grande contingente de trabalhadores de enfermagem sem preparo formal. Ocorreu também, um aumento dos cursos para auxiliares de enfermagem, regulamentados na década de cinqüenta, atendendo assim, às necessidades do mercado.

A organização dos hospitais incorporou as premissas da teoria clássica da administração de Taylor e de Fayol. Nesse contexto, a enfermeira assumiu a responsabilidade de possibilitar e controlar o cumprimento de normas e rotinas, via de regra determinadas pela autoridade dos médicos e dos administradores.

A assistência de enfermagem passou a ser guiada por premissas de método de trabalho funcional, onde importa o cumprimento de tarefas e a execução de procedimentos técnicos e rotineiros.

Os avanços tecnológicos foram progressivamente incorporados pelos hospitais, principalmente pelas unidades especializadas que começaram a ser implantadas na década de setenta.

Assim com SILVA, RIBAS-GOMES e ANSELMI(22), entendemos que essa situação ampliou a oferta de serviços para o enfermeiro na área hospitalar, intensificando as atividades de organizaçåo, planejamento dos senviços e supervisão do pessoal auxiliar.

No Brasil, na década de setenta, o processo de enfermagem passou a ser utilizado nas escolas, tendo por base as propostas de Wanda Horta.

Autores como SILVA(20), OSAWA(18), CATELLANOS(5), entre outros, relatam experiências de aplicação dessa metodologia de assistência em hospitais brasileiros.

Em alguns serviços que conseguiram implementar o processo de enfermagem, esse geralmente não se deu de forma definitiva. Em muitas situações essa metodologia passou a ser aplicada como uma atividade burocrática. Em unidades especializadas, com número reduzido de leitos e com recursos humanos adequados em termos de qualidade e quantidade, parece haver possibilidade para o seu desenvolvimento.

Desse modo, neste estudo pretendemos analisar a prática de enfermagem em uma Unidade de Queimados a partir de dados coletados em estudo anterior, quando o processo de enfermagem era aplicado nessa unidade em très fases: Histórico, Prescrição e Evolução de Enfermagem.

\section{METODOLOGIA}

Escolhemos como fonte de informação dados obtidos em um estudo anterior, que teve como objetivos analisare reformular a prática do processo de enfermagem em uma Unidade de Queimados. Para o alcance desses objetivos desenvolveu-se um plano de atividade educativa com um grupo de enfermeiros dessa Unidade composto por. 01 diretor de senviço; 01 enfermeiro chefe; 
01 enfermeiro encarregado e 06 enfermeiros(19).

O Esquema ao Arco propostos por CHARLES MAGUEREZ(14) foi utilizado como um guia no planejamento das atividades educativas. Esse esquema pedagógico compreende cinco fases: observação da realidade; levantamento de pontos-chave; teorização; hipótese de solução e aplicação.

Nesse momento utilizamos apenas os dados obtidos nas duas primeiras fases desse esquema: a observação da realidade e o levantamento de pontos-chave.

A observação da realidade consiste no levantamento de todos os dados da realidade e na seleção dos aspectos a serem considerados na solução das ques-tões levantadas. Na fase seguinte, e construido um modelo reduzido da realidade orientado pela escolha dos aspectos característicos mais importantes para a solução do problema: os pontos-chave ${ }^{(14)}$.

Nessas duas fases, foram utilizadas três atividades de ensino aprendizagem: 1) apresentação do filme Caminhos Cruzados: a história de uma enfermeira*, seguida de uma discussão em pequenos grupos: 2) aplicação da técnica Tempestade de Idéias e 3) análise e discussão dos registros de enfermagem em dois prontuários de pacientes internados na Unidade de Queimados. Através dessas atividades que estão descritas no item 3 a seguir, pretendeu-se trazer a realidade ao local de aula e estimular as discussões(14).

Os dados aqui apresentados foram coletados através da técnica de observação participante durante as discussões realizadas com os enfermeiros com o desenvolvimento de cada atividade, e anotados através de registro cursivo com papel e lápis, pelo autore por um enfermeiro membro do grupo. Os dados obtidos foram comparados e transcritos em um único registro pelo autor e submetidos a aprovação desse enfermeiro(19).

\section{DESCRIÇÃO DAS ATIVIDADES DESENVOLVIDAS E ANÁLISE DOS DEPOIMENTOS DOS ENFERMEIROS}

\subsection{Projeção e discussão do filme}

A apresentação do filme estimulou uma reflexão sobre a escolha da profissão e sobre o papel do enfermeiro. O filme apresentado focaliza uma enfermeira que pensa em deixar a profissão e mostra situações que fazem parte do dia a dia do enfermeiro, como as frustrações, as dificuldades no relacionamento com médicos e pacientes, a satisfação pelo trabalho bem feito e a recompensa profissional(19).

Seguiu-se a essa apresentação uma discussão em grupo. A seguir destacamos alguns depoimentos registrados durante a realização dessa atividade(19).

E -** Tenho vontade de largar a enfermagem por insatisfação com tudo: salário, horário, mas o cuidado me prende.

E-Escolhemos a profissão sem saber o que vamos fazer, quanto ganhamos, a maior parte das pessoas escolhe a profissão por status e nåo por ideal.

E - O jeito que o paciente falou comigo outro dia: "Vá lá e pega essa cadeira". É difícil aceitar essa agressividade.

E - Pacientes agressivos irritam a gente, às vezes fico pensando - Como estará a C. hoje? Não sabemos trabalhar com isto.

E - Tem dia que saio daqui irritada e em casa ninguém entende e não aceitam que contemos coisas tristes.

E - Quando o médico me disse que enfermeira não serve prá nada, pensei em desistir. "Enfermeira só senve prá pegar no pé do médico" ele disse. Fico pensando se estudei prá isso.

E - Muitas vezes os médicos questionam as informaçöes que damos.

E - O nosso serviço é meio braçal, serviçale isso incomoda as pessoas.

E - O médico cura, a enfermeira cuida, nåo concordo muito com isto.

\footnotetext{
* Caminhos Cruzados: a história de uma enfermeira. Dartnell SIAMAR. 27 min., son., calor. (filme).
} 


\section{E - O notumo me dá muito sono.}

E - Às vezes fico triste pensando no céu azul, no sol, no clube que estou perdendo, no churrasco... Se for domingo à tarde entåo!

Ao entrar na faculdade, muitas vezes, 0 aluno de graduação em enfermagem desconhece aspectos importantes da profissão que acaba de escolher. Quando recém-formado, ao depararse com o mercado de trabalho, descobre que tem expectativas diferentes das da instituição(16).

O trabalho do enfermeiro não tem sido reconhecido como atividade básica e essencial, o que pode ser constatado pela escassez de oportunidades de promoção profissional, baixos salários, extensas jomadas de trabalho e falta de participação nas decisões ${ }^{(9)}$.

A distribuição da jornada de trabalho na enfermagem é uma situação que tem gerado insatisfaçōes. De acordo com MOURA(17), essa realidade é agravada pela inexistência, nas instituições de saúde, de planos de cargos e salários.

De um modo geral, a remuneração do pessoal que trabalha na área de saúde tem sido insuficiente. No que se refere a enfermagem essa situação é ainda pior. Segundo estudos da fundação Kellogg(9), os enfermeiros na maioria dos países latino-americanos, recebem uma remuneração mais baixa que os demais profissionais do setor saúde, com igual preparação.

Na nossa prática, observamos que essa situação ocorre principalmente em relação a equipe médica quanto ao salário, distribuição e extensão da jomada de trabalho.

Uma outra situação que leva a insatisfação é o baixo prestígio social da profissão.

A distribuição do poder nos serviços de saúde tem gerado distinções de salário e de prestígio profissional, favorecendo determinadas profissões que ocupam posições hegemônicas, em detrimento daquelas com menor poder de negociação na defesa de seus direitos(7).

O poder, nas instituições de saúde, está concentrado na equipe médica e os enfermeiros sentem falta de autonomia ${ }^{(9)}$.

Para MOURA(16), a escolha da carreira de enfermagem tem sido, muitas vezes, uma solução para aqueles que não conseguem entrar em outros mercados de trabalho, considerados mais nobres na área de saúde.

Uma outra questão é o fato de que $95 \%$ da força de trabalho na enfermagem ser constituida por mulheres o que, no Brasil, ainda se considera como condição secundária(17).

Assim como BARROS(2), entendemos que a situação da enfermagem como uma profissão feminina também gera problemas, porque a desvalorização que a força de trabalho feminina tem na sociedade é muito concreta, e o enfermeiro se relaciona com o médico assumindo a mesma posição subaltema.

Quando é abordada a questão do trabalho manual realizado pelos enfermeiros, esse aparece como uma atividade serviçal, braçal e isso incomoda as pessoas. Ao mesmo tempo, observa-se que esses profissionais encontram satisfações no cuidado direto aos pacientes, quando afirmam:

E - Porque a enfermeira cuida direto do paciente é que o cuidado daqui é melhor.

E - O nosso ideal é cuidar.

E - O compromisso que temos com a profissão é que faz a gente prestar esse cuidado.

E -...O enfermeiro cuida ou tenta cuidar num todo.

E - Às vezes, os funcionários năo aceitam que a gente năo consegue fazer todos os cuidados e a gente tem tantas coisas para resolver.

E - A gente participa do curativo, verifica sinais vitais, diurese...

\section{E - Eu sempre ajudo no material.}

Os enfermeiros afirmam que executam cuidados diretos, mas o que se observa na realidade é que, muitas vezes, ele participa realizando parte desse cuidado que está fragmentado.

Assim, auxilia os outros profissionais e ocupacionais de enfermagem a executarem atividades rotineiras previstas nos manuais,ou prescritas pelos médicos.

Quando assumem atividades administrativas, estas visam muito mais facilitar o trabalho de outros profissionais na realização de suas tarefas na unidade de intemação, do que concretizar os objetivos do seu próprio serviço(23).

A afirmação de SILVA(21) sobre a ambigüidade do Status-papel do enfermeiro, parece 
bastante atual. Essa ambigüidade está calcada no dilema: cuidado direto ao paciente $x$ atividades de supervisăo e administraçăo.

Para a autora(21),

ao mesmo tempo em que a enfermagem se intelectualiza e/ou se burocratiza, ela passa a ocupar uma posiçăo cada vez mais marginal na equipe de saúde, em relação as demais categorias de enfermagem.

É possivel que esse distanciamento ocorra em função da dicotomia entre 0 administrar e 0 cuidar. Entendendo-se nesse contexto, a administração desvinculada do cuidar e 0 assistir como a execução de rotinas e prescrição médica, como mencionou-se anteriormente.

LEOPARDI(13) afima que a suposiçăo de que o bom profissional é aquele que pơe a måo na massa, fica na cabeceira do paciente prestando cuidado direto, é um fator ideológico que influencia a prática do enfermeiro.

Observa-se que essa suposição parte tanto dos outros profissionais e ocupacionais de enfermagem, como do próprio enfermeiro.

No dia a dia das unidades especializadas, pode-se observar que os enfermeiros que priorizam outras atividades em detrimento do cuidado direto, são criticados pelos outros membros da equipe de enfermagem.

Entendemos que o enfermeiro deveria assumir o gerenciamento do cuidado e que essa atividade envolve o planejamento de recursos humanos, de materiaisie do próprio cuidado.

\subsection{Tempestade de Idéias}

Neste momento, o grupo foi solicitado que diante das palavras assistência de enfermagem expressassem em frases curtas ou palavras as idéias sugeridas diante do assunto, e o mesmo procedimento foi repetido diante das palavras processo de enfermagem. As idéias apresentadas foram registradas em cartazes e discutidas pelo grupo(19).

Nos discursos apresentados a seguir, podese observar que os enfermeiros acreditam que 0 paciente é assistido de forma planejada e que esta assistência é fruto de um trabalho em equipe.
E - O paciente é visto como um todo.

E - Essa assisténcia é fruto de um trabalho em equipe.

E - É uma assistência individualizada.

E - O tratamento que dou para F. é diferente do que dou para $D$., porque săo pessoas diferentes com valores diferentes.

E - Temos dificuldades em lidar com os aspectos emocionais.

E - O apoio emocional é uma coisa que vem do aprendizado.

E - Faltam recursos pra atender os aspectos emocionais.

E - É uma assisténcia planejada.

Em algumas falas o enfermeiro afirma que 0 paciente é atendido como um todo, mas em seguida reconhece que tem dificuldade em lidar com os aspectos emocionais.

Desse modo, a finalidade dessa assistência assistir ao paciente como um todo e de forma individualizada parece estar idealizada(19).

Sobre essa questão WOLF, BOLAND e AUKERMAN(24) afirmam que os enfermeiros tem sido ensinados a identificare satisfazer todas as necessidades dos pacientes e que ficam frustrados quando não conseguem. Por outro lado, segundo essas autoras, os pacientes não esperam que todas as suas necessidades sejam satisfeitas, mas somente aquelas que eles consideram importantes.

Segundo CAMPEDELLI(3), os enfermeiros têm demonstrado que desejam sistematizar o cuidado, individualizar o paciente, administrar a assistência, supervisionar e assumir o cuidado junto com a equipe de enfermagem, mas a utilização de uma metodologia de assistência, na prática, tem pouca representativi- dade. Nas unidades em que se consegue implementar um método de assistência, esta não ocorre de forma definitiva esbarrando em muitas dificuldades.

Essas dificuldades estão relacionadas com a falta de conhecimentos dos enfermeiros sobre o processo de enfermagem, com a organização do trabalho na enfermagem onde predomina a abordagem funcional e com a relação com os outros profissionais e ocupacionais de enfermagem. 
Os métodos tradicionais de trabalho na enfermagem, dominados por rotinas, contribuem para um desempenho automático da prática, inibindo o espirito inquisidor(8).

Concordamos com WOLF, BOLAND e AUKERMAN(24) quando afimam que muitas das rotinas que dirigem a nossa prática são implementadas destituídas de análise quanto a sua contribuição para a qualidade do cuidado. Muitos dos nossos modelos de cuidado estão baseados na forma como eles sempre foram feitos e não em pesquisas.

HENDERSON(11) afirma que os enfermeiros americanos na década de 60 , tendiam a ajustar seus pacientes às rotinas institucionais, mais do que promover programas de cuidados que visassem a satisfação de necessidades e dese jos dos pacientes. Essa situação ainda é muito presente nas instituições de saúde brasileiras. Através das falas dos enfermeiros, observa-se que o tratamento das lesões provocadas pela queimadura parece ter prioridade sobre os outros problemas que o paciente possa estar apresentando. Esses são avaliados durante a realização da tarefa principal: fazer o curativo.

\section{E - Quando vocé recebe o paciente e desenvol-} ve o curativo vocé vai avaliando as necessidades, sendo que essa avaliação não precisa necessariamente de perguntar, mas de avaliar visualmente...

E - Mas se você perguntar como está a retração do F. ou o curativo da C., todo mundo sabe.

Desse modo, parece que o paciente não é o centro da assistência de enfermagem e que esta compreende a realização de tarefas que são consideradas importantes para o seu atendimento, deixando para segundo plano a individualidade do ser humano(3).

\subsection{Análise dos Registros de Enfermagem nos Prontuários de Pacientes Inter- nados}

Nesta última atividade foi solicitado ao grupo de enfermeiros que formassem dois sub-grupos e analisassem os registros de enfermagem de dois prontuários de pacientes internados na Unidade de Queimados. Essa análise foi orientada pelas seguintes questões:

Todos os fatos estão registrados?
Existe correlação entre os fatos registrados? As açסes prescritas têm relaçåo com os problemas registrados na coleta de dados e na evolução de enfermagem? A evolução de enfermagem fomece dados para uma avaliação da eficácia das ações prescritas?(19)

As conclusões dos dois grupos foram semeIhantes e estão apresentadas a seguir:

E - Nas anotaçס̋es que lemos encontramos anotaçס̄es incompletas e informaçסes erradas que não correspondiam a realidade.

E - Nem todos os fatos estavam registrados $e$ não havia registro da coleta de dados. $A$ primeira anotação de enfermagem não fomecia dados suficientes.

E - O instrumento de coleta de dados é ambiguo, dá margem à várias interpretaçס̃es, o que pode justificar os dados não verdadeiros.

E - A prescriçăo de enfermagem não tem relação com a primeira anotação.

E - Existem prescriçסes que eståo presentes e depois desaparecem e voltam a aparecer sem explicaçס̃es.

E - As prescriçסes eståo sendo feitas sobre os aspectos fisicos do paciente e também sobre rotinas.

\section{E - Tem muita prescriçåo sem checar.}

E - Na prática, fazemos uma prescrição e evolução mal feitas.

Neste momento os enfermeiros têm uma percepção mais objetiva da realidade, observam a deficiência está fragmentada e que não consideram a individualidade do paciente. A prescrição compreende cuidados rotineiros, restringindo-se aos aspectos físicos.

Muitas vezes, a utilização do processo de enfermagem ocorre de forma inadequada omitindo-se passos importantes. Outras vezes, cada etapa é cumprida como um ritual ou como uma atividade burocrática e assim como nos manuais de normas e rotinas prescreve-se um assistência desvinculada do paciente.

Para CARVALHO e CASTRO(6), a transformação do processo de enfermagem em mito e do desenvolvi- 
mento da metodologia em ritual, desprovidos de significados para os sujeitos envolvidos no processo, e para a enfermagem propriamente dita, é um equívoco que às vezes ocorre.

Nas falas dos enfermeiros pode-se observar que faltam conhecimentos sobre o processo de enfermagem:

E - Falta estímulo para fazer o histórico, um retorno sobre o porque fazer, saber usar. A propria equipe nåo lê o histórico, falta conhecimento.

E - Temos barreiras contra o historico.

E - O roteiro do historico é chato, confuso.

E - Está faltando na prescriçăo a individualização do paciente.

Algumas vezes, a coleta de dados é realizada apenas como um ritual, desvinculada das fases seguintes, não atendendo ao estabelecimento de diagnóstico ou pelo menos a um levantamento de problemas, tornando-se desnecessária. Nesse contexto, a prescrição de enfermagem é realizada contemplando apenas atividades de rotina.

\section{CONSIDERAÇÕES FINAIS}

Na análise da prática de enfermagem nessa Unidade, observa-se que os enfermeiros estão insatisfeitos com os salários, a jornada de trabaIho, o relacionamento médico $x$ enfermeiro $e$ com as situações que envolvem o sofrimento e a agressividade dos pacientes.

O cuidado direto parece consistir em uma fonte de satisfação para esse profissionais, mas ao mesmo tempo essa atividade é considerada braçal, serviçal, e parece estar representada por tarefas como fazer o curativo, verificar a diurese, os sinais vitais.

O enfermeiro está dividido entre a realização desses cuidados e os problemas que tem que resolver.

Quanto ao planejamento da assistência ob- serva-se que esse foi ajustado às rotinas, e não às necessidades do paciente.

Em muitas instituições de saúde do Brasil, o que é esperado do enfermeiro é que organize o trabalho, estabelecendo rotinas em conformidade com as normas ditadas pelos médicos e administradores, de forma que os profissionais e ocupacionais de enfermagem saibam o que fazer, como fazer e quando fazer.

Assim, se as rotinas estão estabelecidas, cabe ao enfermeiro garantir que esta engrenagem funcione, resolvendo os problemas que possam interferir nesse ambiente.

A implementação do processo de enfermagem pressupõe a modificação dessa situação, já que essa metodologia de assistência implica em trabalho de equipe e desse modo, envolve todos os profissionais que assistem paciente. Para que esse método de trabalho possa ser desenvolvido nos serviços de enfermagem, muitas mudanças deverão ocorrer.

Nesse contexto, parece haver uma tendência para administrações participativas em função da democratização das relações sociais, da velocidade das mudanças, aumento do nivel educacional, intensidade da comunicação e desenvolvimento da consciência de classe e agrupamentos profissionais(15).

Se o enfermeiro quer diminuir sua dependência das rotinas, como um método de organização do cuidado, enquanto gerente dos serviços de enfermagem deverá assumir a liderança no processo de transformação desses serviços, e para tanto há necessidade de educação continuada em serviço.

As propostas de educação continuada necessitam considerar a realidade da organização É importante considerar, como diz KURGANT(12), que o individuo que está na organização é o mesmo que está na sociedade. As condiçס̃es económicas, politicas, culturais e de saúde da sociedade são fatores, se não determinantes, intervenientes nessa organização. 


\section{REFERÊNCIAS BIBLIOGRÁFICAS}

1. ANGERAMI, E.L.S. A construçăo do saber em enfermagem. In: Jornada Nacionale de Investigacion en Enfermeria: Concepcion, 1991, 16p (datilografado).

2. BARROS, E.M.P. Administraçáo da Assistência de Enfermagem e Recursos Humanos. In: Ciclo Nacional de Administraçăo em Enfermagem. Maringá. 9-12 outubro, 1989, Anais... p.63-75.

3. CAMPEDELLI, M.C. org. Processo de Enfermagem na prática. Sáo Paulo: Ática, 1989.

4. CAMPOS, G.W.S. Planejamento sem normas. Săo PauIo: Hucitec, 1989.

5. CASTELLANOS, B.E.P. Aplicaçato do processo de enfermagem no cuidado do paciente na Unidade de Centro Cirúrgico. Rev. da Escola de Enfermagem da USP. Săo Paulo. n.3. 1978.

6. CARVALHO, V. e CASTRO, I.B. Reflexóes sobre a prática de enfermagem. In: Congresso Brasileiro de Enfermagem XXXI. Fortaleza. 11 de agosto de 1979. Anais... p.51-59.

7. COFEN - Associaçăo Brasileira de Enfermagem. O exerclcio da Enfermagem nas instituiçס̃es de Saúde do Brasil. v.1, 1985.

8. FRETWEL, J.E. Hospital ward routine: friend foe? Journal of Advanced Nursing. v.5, 1980. p.625-636.

9. FUNDACION W.K. KELLOG. Enfermeria del siglo XXI in America Latina. 1 ed. 1991. 42p.

10. GERMANO, R.M. Educação e ideologia da enfermagem no Brasil. 2. ed. Săo Paulo: Cortez, 1984, 118p.

11. HENDERSON, $V$. The nursing process - is the tille right? Joumal of Advanced Nursing. n.7, 1982, p.103-109.

12. KURGANT, P. Educaçăo continuada: caminho para a qualidade. Rev. Paul. Enf., v.12, n.12, mai/ago 1993. p.66-71.

13. LEOPARDI, M.T. Método de assisténcia de enfermagem: análise da utilizaçăo do instrumento no processo de trabalho. Ribeirăo Preto, 1991. 178p. Tese (Doutorado). Escola de Enfermagem de Ribeiráo Preto - USP.
14. MAGUEREZ, C. Elementos para uma pedagogia de massa na assisténcia técnica agrícola. Relatório apresentado à Coordenadoria de Assistência Técnica Integral da Secretaria da Agricultura do estado de Săo Paulo. Campinas. 1970 (datilografado).

15. MOTTA, P.R. A ciencia e a arte de ser dingente. 3. ed. Rio de Janeiro: Record, 1991.

16. MOURA, M.L.A. Quem somos? Para onde vamos? In: Ciclo de Debates sobre a Assistência de Enfermagem. Sáo Paulo, 31 de março à 03 de abril. Anais... 1990. p.17-23

17. MOURA, M.L.A. Situaçăo atual dos recursos humanos de enfermagem no Brasil. Rev. Paulista de Enfermagem. v.12, n.2, mai/ago 1993. p.53-55.

18. OSAWA, C. Implantaçăo e desenvolvimento do processo de enfermagem em UTI. In: Ciclo de Debates sobre a Assistência de Enfermagem, I, Săo Paulo, 1988. Anais... p.46-53.

19. ROSSI, L.A. O Processo de Enfermagem em uma Unidade de Queimados: análise e reformulaçáo fundamentadas na pedagogia da problematizaçăo. Ribeirăo Preto. 1992. Dissertaçăo (Mestrado). Escola de Enfermagem de Ribeirăo Preto - USP, 1992.

20. SILVA, S.H. da et al. Implantaçăo e desenvolvimento do Processo de Enfermagem num hospital escola. In: Ciclo de Debates sobre a Assistência de Enfermagem. I, Såo Paulo, 1988. Anais... p.41-5.

21. SILVA, G.B. da. Desenvolvimento da enfermagem - correlaçăo dos problemas da profissăo e da mulher na sociedade. In: Congresso Brapileiro de Enfermagem, XXXI, Fortaleza, 5-11 de agosto de 1979. Anais.. p.27-32.

22. SILVA, E, RIBAS-GOMES, E.L., ANSELMI, M.L. Enfermagem: Realidade e Perspectiva na Assistência e no Gerenciamento. Rev. Lat. Amer. Enf. Ribeirăo Preto, v.1, n.1, p.59-63, jan 1993.

23. TREVIZAN, M.A. Enfermagem hospitalar, administração e burocracia. Brasilia: UNB, 1988

24. WOLF, G.A., BOLAND, S., AUKERMAN, M. A Transformational model for the practice of professional nursing Joumal of Nursing Administration. v.24, n.4, 1994. p.51-57.

Recebido para publicação em 27.05.94 